\title{
Thin-spread Colonies
}

\author{
Sho Saito and Hanako Kurai
}

Key words: Helicobacter cinaedi, thin-spread colonies

(Intern Med 55: 2325, 2016)

(DOI: 10.2169/internalmedicine.55.6926)

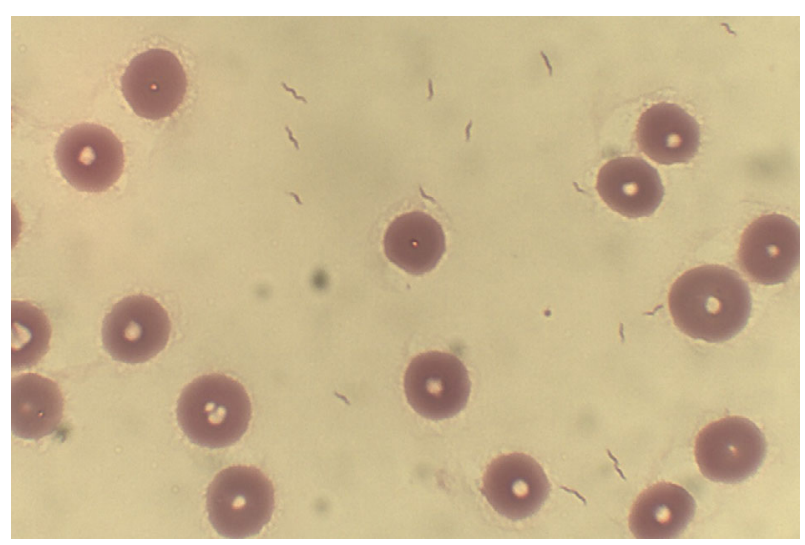

Picture 1.

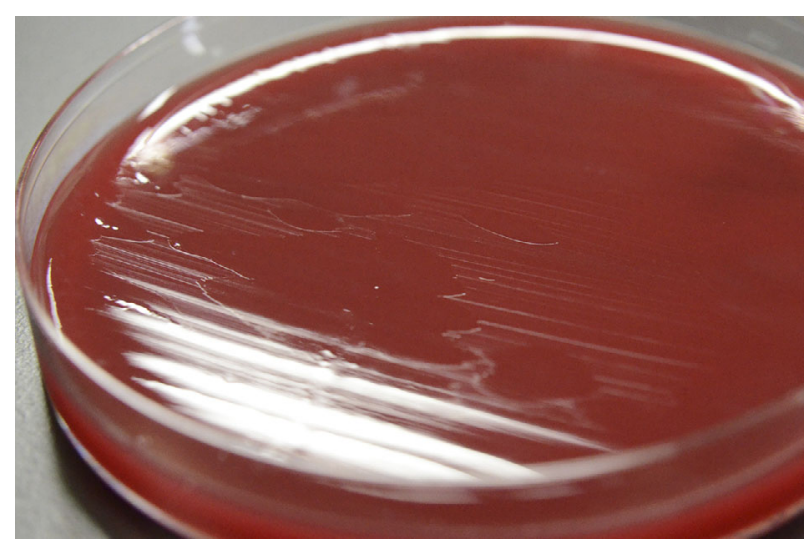

Picture 2.
A 61-year-old Japanese man with left lower thigh liposarcoma presented with fever and chills three days after receiving doxorubicin and ifosfamide chemotherapy. Cefepime was administered intravenously after two sets of blood cultures were obtained. Three days later, spiral-shaped, gramnegative bacilli, a shape suggestive of Helicobacter sp. or Campylobacter sp., were isolated from the blood cultures (Picture 1). A microaerobic culture was obtained and thinspread colonies were observed on the blood agar plate (Picture 2). A diagnosis of Helicobacter cinaedi was confirmed using the $16 \mathrm{~S}$ rRNA gene sequences, and the patient was treated for a total of 21 days. However, after another chemotherapy course he experienced two recurrences, with positive blood cultures each time. He underwent a below-the-knee amputation for liposarcoma, and no recurrence was observed at a 1 year follow-up examination. $H$. cinaedi is a rare pathogen which is mostly observed in immunocompromised patients (1). It has a high potential for recurrence (2).

The authors state that they have no Conflict of Interest (COI).

\section{References}

1. Araoka H, Baba M, Kimura M, Abe M, Inagawa H, Yoneyama A. Clinical characteristics of bacteremia caused by Helicobacter cinaedi and time required for blood cultures to become positive. J Clin Microbiol 52: 1519-1522, 2014.

2. Kawamura Y, Tomida J, Morita Y, Fujii S, Okamoto T, Akaike T. Clinical and bacteriological characteristics of Helicobacter cinaedi infection. J Infect Chemother 20: 517-526, 2014.

Division of Infectious Diseases, Shizuoka Cancer Center Hospital, Japan

Received for publication December 5, 2015; Accepted for publication December 20, 2015

Correspondence to Dr. Sho Saito, s.saito@scchr.jp

(C) 2016 The Japanese Society of Internal Medicine Journal Website: http://www.naika.or.jp/imonline/index.html 